\title{
Aromatic Profile of White Sweet Semi-sparkling Wine from Malvasia di Candia Aromatica Grapes
}

\author{
G. Montevecchi ${ }^{1}$, F. Masino ${ }^{1,2, *}$, G. Vasile Simone ${ }^{2}$, E. Cerretti ${ }^{2}$, A. Antonelli ${ }^{1,2}$ \\ (1) Centre for the Development and Improvement of Agri-Food Resources - BIOGEST-SITEIA, University of Modena and \\ Reggio Emilia, via G. Amendola 2 (Pad. Besta), 42122 Reggio Emilia, Italy \\ (2) Department of Life Science, University of Modena and Reggio Emilia, via G. Amendola 2 (Pad. Besta), 42122 Reggio \\ Emilia, Italy
}

Submitted for publication: December 2014

Accepted for publication: February 2015

Key words: Malvasia di Candia aromatica, white sweet semi-sparkling wine, aromatic compounds, gas chromatographic analysis

\begin{abstract}
Malvasia di Candia aromatica is an aromatic white grape (Vitis vinifera L.) cultivar that grows in the Emilia-Romagna and Lombardy regions and is used for manufacturing sweet and dry white wines. A study of the gas chromatography analysis of the aromatic profile was carried out during the winemaking process for the production of a sweet semi-sparkling wine. At the end of the monitoring period, free monoterpenic and fermentative compounds characterised the aromatic profile of the wine. Linalool and nerol had a similar concentration, while the main fermentative compounds were the isoamyl alcohols, 2-phenylethanol, medium-chain fatty acids and their corresponding ethyl esters, and isoamyl acetate. All these compounds showed increasing trends during the fermentation process. The amount of linalool at the end of the monitoring period exceeded the threshold of perception, hence contributing to the floral scent of the wine. The higher alcohols (concentration up to $200 \mathrm{mg} / \mathrm{L}$ ) and their esters also made a pleasant contribution to the aroma definition. Finally, the low temperature of fermentation helped to preserve the varietal aroma and enhanced the production of fermentative compounds, with a corresponding restraint of higher alcohols. This work is a first approach to a study of the sweet semi-sparkling wine (vino frizzante) obtained from Malvasia di Candia aromatica grapes. A more detailed investigation is required to understand how to improve the varietal and fermentative aromas of the wine.
\end{abstract}

\section{INTRODUCTION}

Malvasia di Candia aromatica is a grapevine (Vitis vinifera L.) cultivar (cv.) that produces aromatic white grapes (Borsa et al., 2005) and is cultivated in the Emilia Romagna provinces of Piacenza, Parma and Reggio Emilia, while in Lombardy it is cultivated in the area of Oltrepò Pavese (Calò et al., 2006). It is registered in the National Registry of Grapevine Varieties.

In the literature there are specific studies on Malvasia di Candia aromatic, focused on the characteristics of the soil (Zamboni et al., 2009), and on the effects of leaf removal (desuckering) on the composition of the berry (Bavaresco et al., 2008). Other studies include the phenological and productive performance of Malvasia (Giust et al., 2005), the morphological and biochemical characteristics (Costacurta et al., 2005), the secondary metabolites (Borsa et al., 2005), and the genetic inter- and intra-varietal variability (Lacombe et al., 2007; Meneghetti et al., 2012). A sensory study was conducted on wines obtained from the late harvest of Malvasia di Candia aromatica grown in Tuscany (Scalabrelli et al., 2008). The aromatic profile of must and wine from
Colli di Parma Malvasia D.O.C. has also been studied in relation to the amount of assimilable nitrogen available from the yeasts present in the must (Nicolini et al., 2009).

The present work is a first approach to the study of the influence of winemaking technique on the sweet semisparkling wine (vino frizzante) obtained from Malvasia di Candia grapes, an aromatic cultivar, as an expression of its rich and variegated profile, which is comparable to that of Muscat in terms of intensity and bouquet (Costacurta et al., 2005). As far as we know, it is the first time that a systematic approach has been applied to this cultivar. The aim of this study was to investigate the evolution of the volatile fraction during the different stages of the winemaking process used by local manufacturers in order to plan strategies to improve the varietal aromas of the wine.

\section{MATERIALS AND METHODS}

Processing stages and sampling

The experimentation was conducted on samples of Malvasia di Candia aromatica wine, of which the grapes had been harvested from the vineyards around Reggio Emilia. The

*Corresponding author: E-mail address: francesca.masino@unimore.it [Tel.: +390522 522066; Fax: +39 0522 522027]

Acknowledgements: The authors wish to thank Cantina Sociale di Puianello scarl (RE), for supplying the samples and their kind collaboration in the development of the project 
winemaking process was carried out at the Cantina Sociale di Puianello scarl (Puianello di Quattro Castella, RE). The grapes were crushed and stemmed and sulphur dioxide $(80 \mathrm{mg} / \mathrm{L})$ was added to the must with marc and the mixture was divided into two different tanks.

Pectolytic enzyme (EC 3.2.1.15, FCE G Vinozym ${ }^{\circledR}$, Novozymes, Bordeaux, France), devoid of secondary glycosidase activity, was added and the masses were subjected to pellicular maceration for about $12 \mathrm{~h}$ at $8^{\circ} \mathrm{C}$. Then the musts were racked, drained and the marc was pressed. The musts that were obtained were clarified with gelatine $(0.03 \mathrm{~g} / \mathrm{L})$ and silica sol $(0.3 \mathrm{~g} / \mathrm{L})$.

After clarification by centrifugation, the musts were set aside at $10^{\circ} \mathrm{C}$ without further manipulations so that a first spontaneous fermentation started. During the following 11 days, periodic monitoring was carried out and the total (TA) and volatile acidity (VA), alcohol by volume (ABV) and sugar content were measured. Then, the products of the two tanks were combined and the fermentation continued for about a month. Successively, once $4 \%$ ABV was reached and the reducing sugars were at about $100 \mathrm{~g} / \mathrm{L}$, the yeasts were removed by centrifugation and the product was racked into an autoclave for the second fermentation $\left(16\right.$ to $\left.18^{\circ} \mathrm{C}\right)$. In this step, selected active yeasts (Zymaflore X5, Laffort Enologie, Bordeaux, France) were added to the product in order to obtain a sweet semi-sparkling wine. In this way, tumultuous fermentation was prevented and, at the same time, good properties of the wild yeast could be exploited. Moreover, the selected yeasts guarantee a complete fermentation of all sugars. Once about 7\% ABV had been obtained, the yeasts were removed and a final clarification was done, after which the product was bottled. The winemaking process and sampling were carried out according to the diagram in Fig. 1.

\section{Chemicals}

Pure reference compounds and internal standards (IS, 2-octanol) were purchased from Fluka Sigma-Aldrich (Milan, Italy); high-purity solvents were supplied by VWR Srl (Milan, Italy), while diatomaceous earth (Chem TubeHydromatrix TM) was obtained from Varian (DTO Servizi

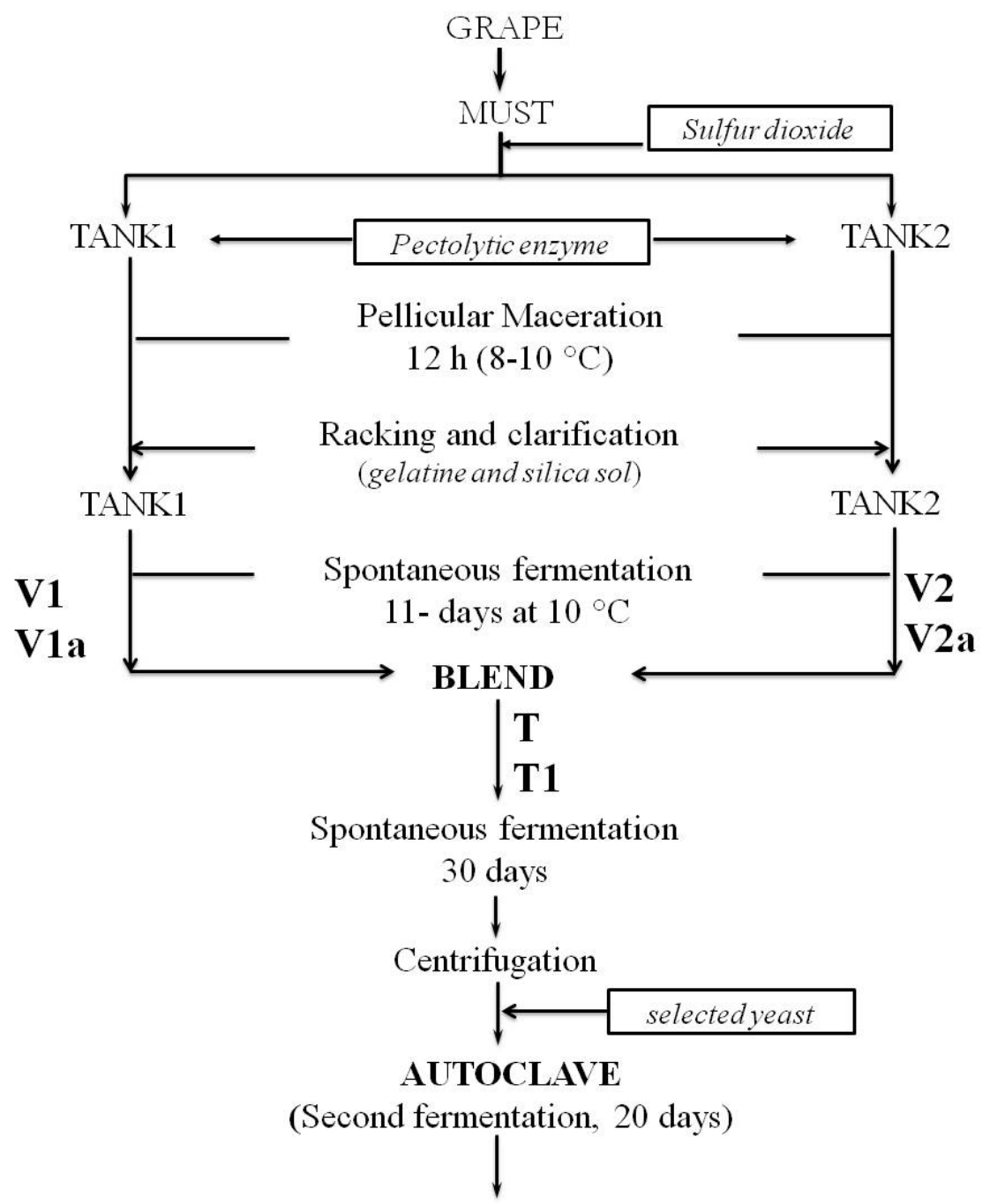

A $\begin{array}{lll}\text { A1 } & \text { A2 A3 }\end{array}$

FIGURE 1

Winemaking process and sampling. First fermentation: V1 and V2 (5 October), V1a and V2a (12 October); blend: T (16 October), T1 (28 October) and clarification; second fermentation in autoclave: A, (4 November), A1 (13 November), A2 (16 November), A3 (20 November). 
TABLE 1

Chemical and physical data of the Malvasia di Candia aromatica wine during the fermentation process. First fermentation: V1 and V2 (5 October), V1a and V2a (12 October); blend: T (16 October), T1 (28 October); second fermentation in autoclave: A (4 November), A1 (13 November), A2 (16 November), A3 (20 November).

\begin{tabular}{|c|c|c|c|c|c|c|c|c|c|c|}
\hline \multirow{2}{*}{ Physicochemical parameter } & \multicolumn{10}{|c|}{ Fermentation process } \\
\hline & V1 & V2 & V1a & V2a & $\mathbf{T}$ & T1 & A & A1 & A2 & $\mathbf{A 3}$ \\
\hline ABV (\%) & 3.43 & 2.15 & 3.65 & 2.40 & 3.70 & 4.02 & 4.39 & 7.02 & 7.10 & 7.34 \\
\hline Reducing sugars $(\mathrm{g} / \mathrm{L})$ & 105 & 104 & 103 & 103 & 106 & 101 & 99 & 53 & 52 & 56 \\
\hline $\mathrm{TA}(\mathrm{g} / \mathrm{L})$ & 4.2 & 4.3 & 5.1 & 4.6 & 4.6 & 5.1 & 5.3 & 5.5 & 6.7 & 7.1 \\
\hline $\mathrm{VA}(\mathrm{g} / \mathrm{L})$ & 0.12 & 0.14 & 0.18 & 0.13 & 0.18 & 0.22 & 0.22 & 0.21 & 0.29 & 0.29 \\
\hline Total $\mathrm{SO}_{2}(\mathrm{mg} / \mathrm{L})$ & 72 & 58 & 72 & 58 & 72 & 68 & 66 & 64 & 62 & 56 \\
\hline $\mathrm{pH}$ & 3.42 & 3.40 & 3.44 & 3.39 & 3.37 & 3.46 & 3.42 & 3.14 & 3.23 & 3.23 \\
\hline
\end{tabular}

Srl, Spinea, VE, Italy). Deionised water was obtained with a Milli-Q purification system (Millipore, Milan, Italy).

\section{Chemical and physical analysis}

$\mathrm{ABV}$, reducing sugars, $\mathrm{VA}, \mathrm{TA}$, total sulphur dioxide and $\mathrm{pH}$ were carried out according to the official methods (Ough \& Amerine, 1988; EU Official Gazette, 1990).

\section{Extraction of aromatic compounds and determination of volatiles by GC/FID and GC/MS}

The method of Gerbi et al. (1992) was adapted as follows: A sample $(20 \mathrm{~mL})$ was previously filtered, and $95 \%$ ethanol was added up to $10 \% \mathrm{ABV}$, along with $50 \mu \mathrm{L}$ of IS solution (2-octanol, $10000 \mathrm{mg} / \mathrm{L}$ ). Then, $15 \mathrm{~g}$ of diatomaceous earth were added to the sample and it was transferred to a mortar, where it was homogenised and poured into a glass column (ID $2.5 \mathrm{~cm}$ ) previously filled with 2 to $3 \mathrm{~g}$ of anhydrous $\mathrm{Na}_{2} \mathrm{SO}_{4}$. The volatile fraction was eluted with $70 \mathrm{~mL}$ of dichloromethane at a flow rate of $2 \mathrm{~mL} / \mathrm{min}$. The extract was stored at $-18^{\circ} \mathrm{C}$ for $60 \mathrm{~min}$ in order to freeze the residual water, and it was subsequently passed through a paper filter with $2 \mathrm{~g}$ of anhydrous $\mathrm{Na}_{2} \mathrm{SO}_{4}$ soaked in extraction solvent. The filtered extract was reduced to about $5 \mathrm{~mL}$ with a Kuderna-Danish concentrator and, finally, to 200 to $300 \mu \mathrm{L}$ with a gentle stream of $\mathrm{N}_{2}$.

The concentrated extract $(1 \mu \mathrm{L})$ was injected into a gas chromatograph GC 9000 Series (Fisons Instruments SpA, Rodano, MI, Italy) equipped with a capillary column Crossbond Mega-wax (polyethylene glycol, $15 \mathrm{~m} \times 0.18 \mathrm{~mm} \mathrm{ID}$, $0.30 \mu \mathrm{m}$ film thickness, Mega snc, Legnano, MI, Italy). The oven temperature was set at $60^{\circ} \mathrm{C}$ and it was increased to $230^{\circ} \mathrm{C}$ at $4^{\circ} \mathrm{C} / \mathrm{min}$ and was maintained at this final temperature for $20 \mathrm{~min}$ (60 min of analysis). The injector (split mode, split ratio of $25: 1)$ and the detector were set at $250^{\circ} \mathrm{C}$. The carrier gas (hydrogen) was set at $80 \mathrm{kPa}(1.31 \mathrm{~mL} / \mathrm{min}$ at $25^{\circ} \mathrm{C}$ ). The chromatograms were acquired and processed using the Chrom-Card 1.15 software (Fisons Instruments SpA, Rodano MI, Italy).

A gas chromatograph (HP 6890 Series, Hewlett-Packard, Waldbronn, Germany) with a split/splitless injection port and coupled with a mass spectrometer (HP 5973 Mass Selective Detector, Hewlett-Packard, Waldbronn, Germany) was operated under the same conditions used for GC/FID analysis. The molecular fragmentation was obtained by electron ionisation (EI). The data were obtained in fullscan mode and the mass-to-charge ratio $(\mathrm{m} / \mathrm{z})$ was recorded between 33 and 300 at an ionisation voltage of $70 \mathrm{eV}$. The ion source temperature was set at $230^{\circ} \mathrm{C}$ and the quadrupole temperature at $150^{\circ} \mathrm{C}$. The chromatograms were acquired and processed using Enhanced Chem Station software (G1701AA Version A.03.00, Hewlett Packard ${ }^{\circ}$ ).

Identification was carried out by comparing the retention times with that of the reference pure standards, injected under the same conditions as the samples, and by mass spectra of pure standards contained in the NIST/EPA/NIH Mass Spectral library (2002 version). The quantification was performed using the internal standard method. All the analyses were carried out in triplicate.

\section{Statistical analysis}

Principal component analysis (PCA) was applied to the autoscaled dataset. Statistical processing was carried using Statistica software version 8.0 (StatSoft Inc., Tulsa, OK, USA).

\section{RESULTS AND DISCUSSION}

\section{Chemical and physical analysis}

The main fermentation parameters (ABV, reducing sugars, TA, VA, total $\mathrm{SO}_{2}$ and $\mathrm{pH}$ ) are shown in Table 1. After a week of fermentation in a tank carried out without starter yeasts (samples V1a and V1b), the ABV and reducing sugars remained almost unchanged. An active fermentation was recorded only after nine days from the racking in the autoclave (sample A1). At the end of the monitoring period, $\mathrm{ABV}$ was around $7.50 \%$.

\section{Determination of aromatic compounds}

Table 2 reports the data of the 48 substances identified in the wine samples during fermentation. The total sum of aromatic compounds showed an increasing trend as a consequence of the fermentation process. The higher alcohols were the most abundant class of compounds and markedly affected the trend of the total sum. Other classes of compounds showed a less regular trend, particularly during the second fermentation in the autoclave, reflecting the complexity of the factors involved in aroma formation.

Varietal aroma compounds ( $\beta$-citronellol, linalool, linalool oxides, nerol and $\alpha$-terpineol) showed a total 


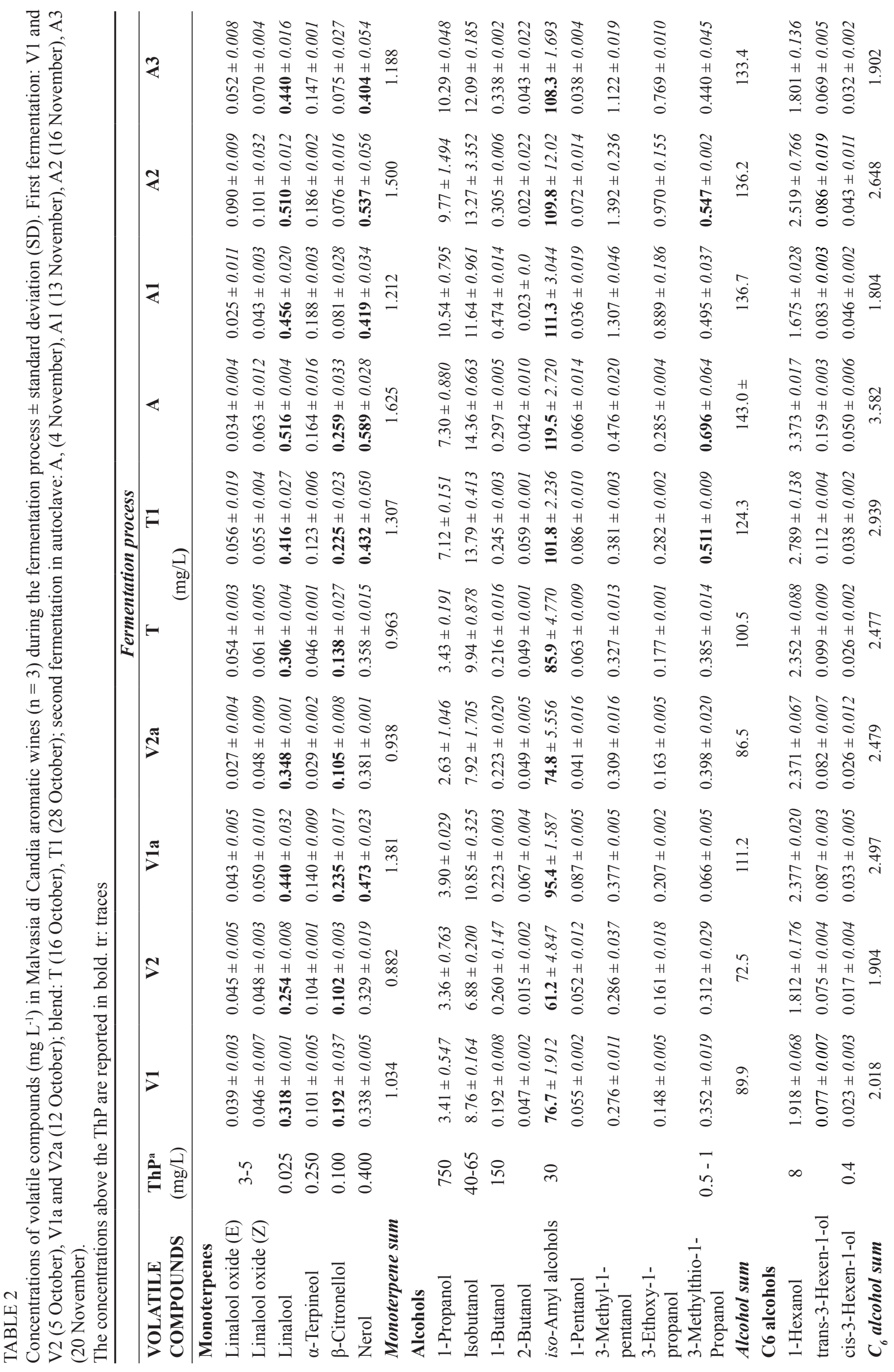




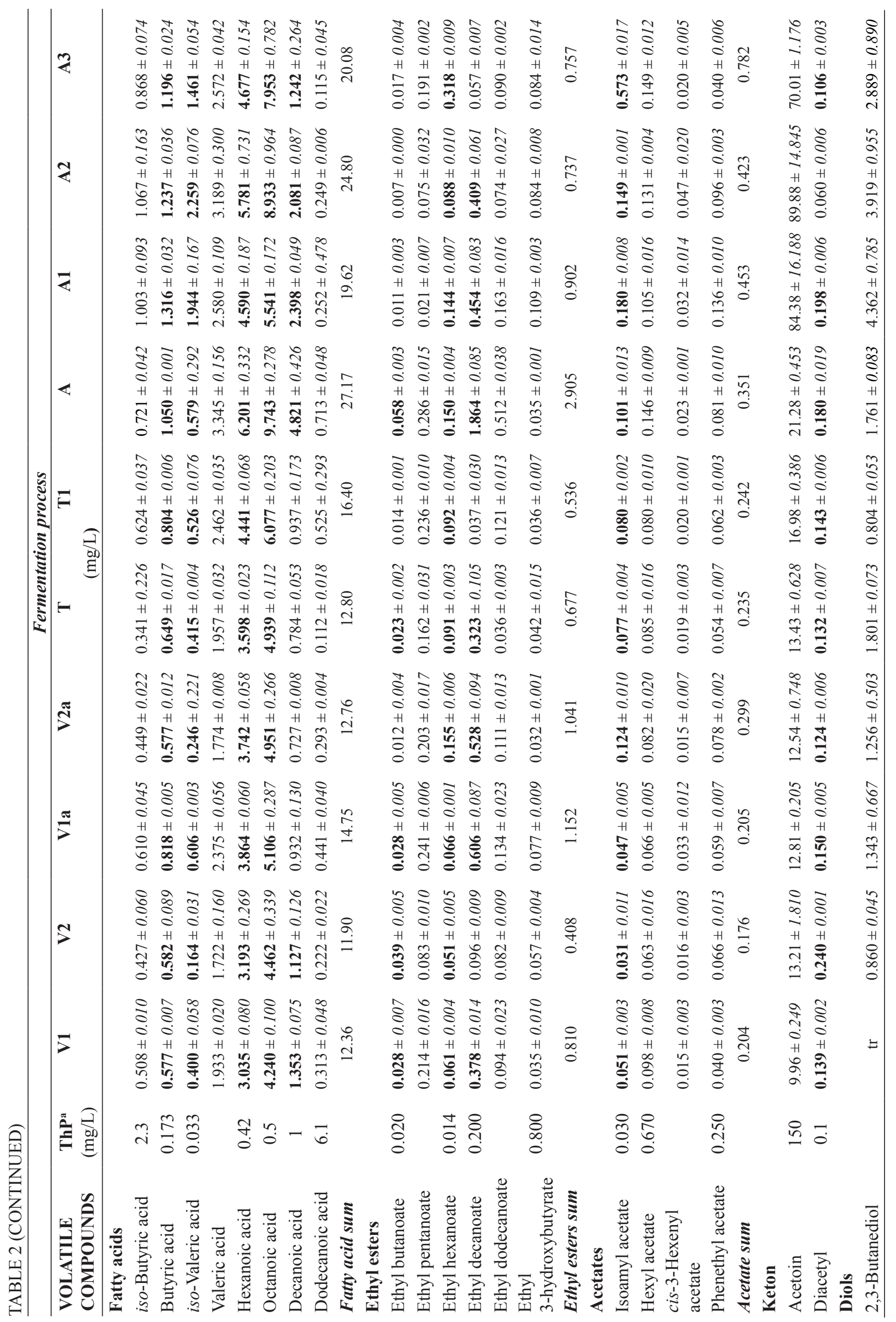




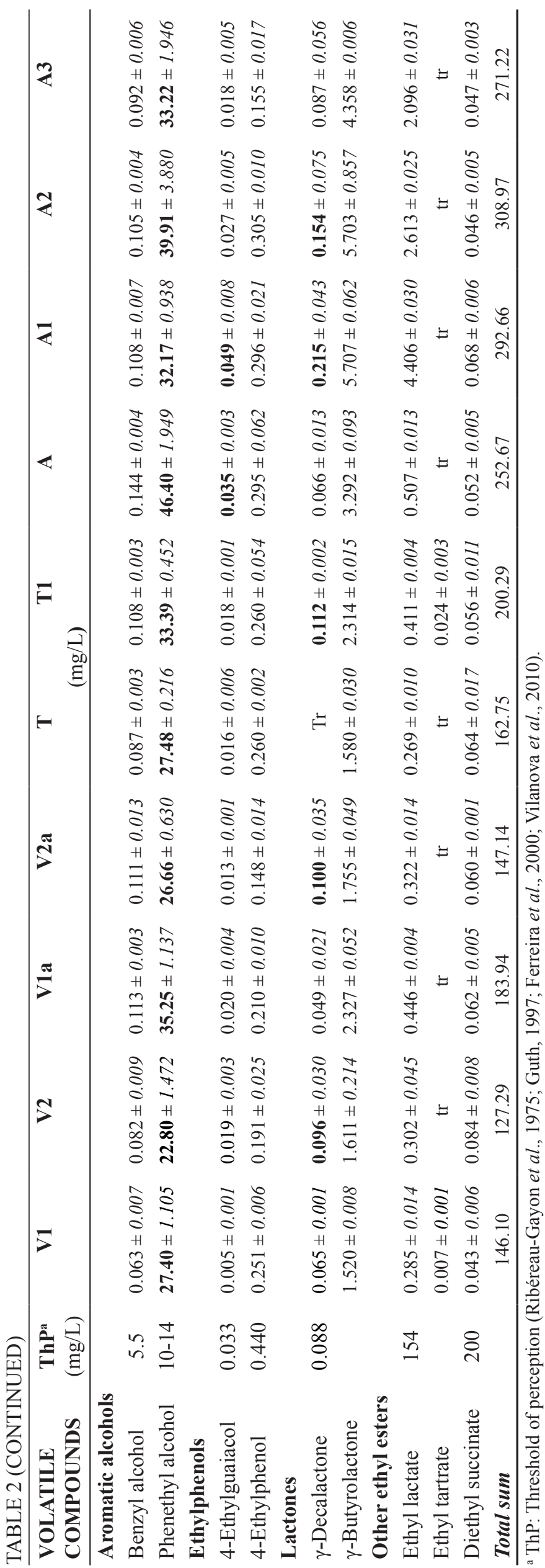

concentration ranging between 0.88 and $1.62 \mathrm{mg} / \mathrm{L}$. These monoterpenes are already present in mature grapes, but they also come from the partial hydrolysis of the glycosylated forms (Gunata et al., 1986). In fact, their trends tended to increase during the early stages of the first fermentation and then slightly decreased during the second fermentation in the autoclave. As a matter of fact, the glycosylated fraction (three to 10 times higher than the free fraction) acts as a reserve of monoterpenes and other aromatic moieties in the wine (Gunata et al., 1988; D’Onofrio, 2011). Linalool is an exception because its free fraction is sometimes higher than the glycosylated one in the ripe grapes (Fenoll et al., 2009). In the analysed samples, nerol had values comparable to linalool, and their concentrations showed variable trends. At the end of the monitoring period, both of them exceeded the threshold of perception (ThP), although nerol settled around its limit value, while linalool reached an odour activity value (OAV) that was quite high (17.6), which helped to give floral scents to the wine (Guth, 1997). In contrast, linalool oxides have higher ThPs (3 to $5 \mathrm{mg} / \mathrm{L}$ ). It is noteworthy that for additive or synergistic effects, the ThP of monoterpenes mixtures is lower than the threshold of each single component (Ribéreau-Gayon et al., 1975).

When the products of the two tanks were blended, the concentrations of $\alpha$-terpineol, and to a lesser extent that of $\beta$-citronellol, decreased. The discrepancies between the terpene content of samples V1a and V2a could be explained by the management of the maceration step. In this step, carried out in winery, it is very likely that the amount of solid and liquid matter was not regularly divided between the two tanks during the pellicular maceration. Thus the different amount of marcs could have had some impact on the terpene content, as many of these substances are on the solid part of the berry. To support this hypothesis, fermentation and $\mathrm{SO}_{2}$ also follow different paths. This could explain the differences in all terpenes, with the exception of $\alpha$-terpineol, which shows a very sharp contrast that does not have a straightforward explanation. In any case, sample $\mathrm{T}$ confirms the anomalous content of this substance. These substances then started increasing again to reach amounts similar to those reported in the literature (Gunata et al., 1986). In fact, on the one hand the terpenes may be subjected to chemical transformation during fermentation, or can be adsorbed by the cell walls of the yeast, or simply stripped by the development of $\mathrm{CO}_{2}$ or lost during technological processes such as centrifugation. On the other hand, free terpenes may be released from their glycosides. Anyway, neither $\beta$-citronellol nor $\alpha$-terpineol exceeded their ThPs at the end of the trial (Ribereau-Gayon et al., 1975; Guth, 1997; Ferreira et al., 2000; Vilanova et al., 2010).

The concentrations of individual monoterpenes were generally higher than that found in the literature for related wines and grapes (Câmara et al., 2004; Borsa et al., 2005; Câmara et al., 2007; Del Caro et al., 2009), while the concentrations of linalool and $\alpha$-terpineol were comparable with what was found by Muratore et al. (2007) in the wine Malvasia delle Lipari.

The alcohols with six carbon atoms are considered substances of pre-fermentative origin, although it seems that they may also be involved in yeasts metabolism (Masino 
et al., 2008). Their importance comes from their herbaceous scent. Among them, 1-hexanol was the most abundant compound (mean $2.30 \mathrm{mg} / \mathrm{L}$ ) and it defined the trend of this class of compounds. The values found for the samples at the end of the monitoring period were comparable to those in the literature (Muratore et al., 2007; Nicolini et al., 2009; Del Caro et al., 2012). Their concentrations showed a slight upward trend during the first fermentation, but an opposite trend was observed during the second fermentation. In any case, none of these compounds exceeded their ThP.

The higher alcohols produced by fermentation were represented mainly by isoamyl alcohols (2- and 3-methyl-1butanol), which increased regularly during the winemaking process up to $200 \mathrm{mg} / \mathrm{L}$, thus making a pleasant contribution to the wine (Rapp \& Mandery, 1986). The OAV at the end of the study was between 3 and 4 .

Among the other alcohols, only 3-methylthio-1propanol exceeded its ThP. Its contribution to the aroma is expressed by a burnt garlic scent or that of cooked cabbage. Phenethyl alcohol (OAV of between 2 and 3) is the most important aromatic alcohol. It originates from both varietal (phenylpropanoid metabolism) and fermentative (Gómez-
Plaza et al., 1999) patterns and provides a pleasant floral note of rose.

The medium-chain fatty acids are fermentation aromas that deserve special attention for their sensory characteristics (Liberatore et al., 2010). Their concentration was almost constant during the first steps of the fermentation, after which their content increased to reach a maximum, followed by a decrease. This decline is attributable to an adsorption on the cell walls of yeasts (Lafon-Lafourcade et al., 1984), as for their corresponding esters. In addition, the production of these substances is related to the temperature. A fermentation temperature of around $25^{\circ} \mathrm{C}$ promotes long-chain fatty acid $\left(\mathrm{C}_{16}\right.$ to $\left.\mathrm{C}_{18}\right)$ biosynthesis. In contrast, a lower temperature of fermentation, such as that used in this experiment, tends to increase the rate of unsaturation at the beginning of the fermentation and reduce the length of the chain to obtain medium-chain fatty acids (Molina et al., 2007; Beltran et al., 2008).

The concentrations of hexanoic, octanoic and decanoic acids were consistent with the data in the literature for aromatic Malvasia wines (Muratore et al., 2007; Nicolini et al., 2009; Del Caro et al., 2012), and significantly exceeded their respective ThPs. In particular, the sum of the

TABLE 3

Loading values for the first three principal components (PC). Loading values (absolute value) higher than 0.70 are reported in bold.

\begin{tabular}{|c|c|c|c|c|c|c|c|}
\hline Aromatic compounds & PC1 & PC2 & PC3 & Aromatic compounds & PC1 & PC2 & PC3 \\
\hline Linalool oxide (E) & 0.34 & 0.08 & -0.63 & Ethyl pentanoate & -0.35 & -0.74 & -0.40 \\
\hline Linalool oxide (Z) & 0.61 & -0.07 & -0.56 & Ethyl hexanoate & 0.46 & 0.17 & -0.28 \\
\hline Linalool & 0.86 & -0.43 & -0.09 & Ethyl decanoate & 0.22 & -0.80 & 0.31 \\
\hline$\alpha$-Terpineol & 0.83 & -0.12 & 0.16 & Ethyl dodecanoate & 0.29 & -0.81 & 0.37 \\
\hline$\beta$-Citronellol & -0.31 & -0.86 & -0.01 & Ethyl 3-hydroxybutyrate & 0.68 & 0.52 & 0.17 \\
\hline Nerol & 0.67 & -0.68 & -0.04 & Isoamyl acetate & 0.52 & 0.36 & -0.40 \\
\hline Propanol & 0.95 & 0.10 & -0.03 & Hexyl acetate & 0.76 & -0.20 & -0.25 \\
\hline iso-Butanol & 0.74 & -0.53 & -0.21 & cis-3-Hexenyl acetate & 0.73 & 0.00 & -0.05 \\
\hline 1-Butanol & 0.79 & 0.29 & 0.47 & Phenethyl acetate & 0.59 & 0.09 & 0.67 \\
\hline 2-Butanol & -0.38 & -0.44 & -0.46 & Acetoin & 0.91 & 0.41 & -0.02 \\
\hline iso-Amyl alcohols & 0.86 & -0.39 & -0.08 & Diacetyl & -0.32 & -0.04 & 0.83 \\
\hline 1-Pentanol & -0.11 & -0.60 & -0.30 & 2,3-Butanediol & 0.89 & 0.32 & 0.13 \\
\hline 3-Methyl-1-pentanol & 0.92 & 0.37 & -0.03 & Benzyl alcohol & 0.45 & -0.67 & 0.24 \\
\hline 3-Ethoxypropanol & 0.92 & 0.37 & -0.05 & Phenethyl alcohol & 0.70 & -0.69 & -0.10 \\
\hline 3-Methylthio-1-propanol & 0.57 & -0.34 & 0.10 & 4-Ethylguaiacol & 0.74 & -0.09 & 0.63 \\
\hline 1-Hexanol & 0.10 & -0.92 & -0.13 & 4-Ethylphenol & 0.47 & -0.38 & 0.26 \\
\hline trans-3-Hexenol & 0.15 & -0.92 & 0.18 & $\gamma$-Decalactone & 0.64 & 0.37 & 0.42 \\
\hline cis-3-Hexenol & 0.83 & -0.48 & 0.16 & $\gamma$-Butyrolactone & 0.97 & 0.19 & 0.08 \\
\hline iso-Butyric acid & 0.96 & 0.10 & 0.00 & Ethyl lactate & 0.82 & 0.45 & 0.27 \\
\hline Butyric acid & 0.98 & 0.04 & 0.04 & Diethyl succinate & -0.36 & 0.28 & 0.66 \\
\hline iso-Valeric acid & 0.92 & 0.32 & -0.07 & $\mathrm{ABV}$ & 0.93 & 0.23 & -0.18 \\
\hline Valeric acid & 0.85 & -0.51 & -0.07 & Reducing sugars & -0.89 & -0.44 & 0.06 \\
\hline Hexanoic acid & 0.84 & -0.49 & -0.04 & $\mathrm{TA}$ & 0.85 & 0.14 & -0.43 \\
\hline Octanoic acid & 0.77 & -0.46 & -0.23 & VA & 0.86 & -0.03 & -0.39 \\
\hline Decanoic acid & 0.55 & -0.62 & 0.39 & Total $\mathrm{SO}_{2}$ & -0.29 & -0.44 & -0.05 \\
\hline Dodecanoic acid & 0.04 & -0.90 & 0.21 & $\mathrm{pH}$ & -0.77 & -0.59 & -0.13 \\
\hline Ethyl butanoate & -0.25 & -0.65 & 0.32 & & & & \\
\hline
\end{tabular}


three acids is critical. The total concentrations of mediumchain fatty acids (4 to $10 \mathrm{mg} / \mathrm{L}$ ) give pleasant notes and contribute to vinosity, while above $20 \mathrm{mg} / \mathrm{L}$ these substances provide unpleasant odours (Shinohara, 1985). In the analysed samples, this critical threshold was overtaken only at the beginning of the second fermentation, but at the end of the monitoring period the total content was as low as $14 \mathrm{mg} / \mathrm{L}$.

Although their concentrations were rather low, ethyl esters and acetates are characterised by ThPs low enough to be appreciated. Most of the ethyl esters of fatty acids, with the exception of ethyl hexanoate, showed behaviour similar to that of the fatty acids, with a peak of maximum concentration of the esters that was not generally consistent with the maximum development of ethanol.

A different behaviour was observed for ethyl hexanoate, whose average concentration was constant during the first fermentation and increased during the second fermentation in the autoclave, reaching a maximum concentration $(0.318 \mathrm{mg} / \mathrm{L})$ in correspondence with the highest ethanol content (sample A3). Moreover, ethyl hexanoate was the only ester exceeding its $\mathrm{ThP}$ in the final sample $(\mathrm{OAV}=23)$ and gives pleasant floral/fruity aromas to wine.

The esters of acetic acid were constant during the fermentation process in the tank, while they increased during the second fermentation in the autoclave. Similar trends have also been reported by other authors (Vianna \& Ebeler, 2001; Miller et al., 2007).

Only isoamyl acetate exceeded its $\mathrm{ThP}$ at the end of monitoring period $(\mathrm{OAV}=19)$. It is associated with banana and apple flavour. However, a cumulative effect could affect the entire perception of acetates, also in this case. Finally, the presence of ethyl acetate, the main congener, was not detected under the analytical conditions applied.

The presence of compounds such as 4-ethylphenol and 4-ethylguaiacol was unusual. In fact, their presence is typical of red wines, while in white wines the corresponding vinyl derivatives are prevalent (Rapp \& Versini, 1996). These compounds also have been observed by other authors in Malvasia di Candia wines (Nicolini et al., 2009), possibly as a result of contamination by Brettanomyces. When the sum of their concentrations exceeds $0.4 \mathrm{mg} / \mathrm{L}$ (Rapp \& Versini, 1996) the wine has an unpleasant note of horse sweat. However, in the examined samples this threshold was never reached, except in the case of 4-ethylguaiacol in some intermediate samples.

To gain an overall vision of the whole sample set, a PCA was carried out on the autoscaled data matrix, composed of the 52 chemical parameters measured for all the samples collected during the winemaking process. The first three principal components (PCs) explained $80.36 \%$ of the total variance of the dataset.

The plot of PC1 (47.39\% of total variance) vs. PC2 (22.97\% of total variance) (Fig. 2) showed that samples collected in different steps of the winemaking process were grouped in different clusters because of the evolution of the aromatic compounds and the modification of the chemical composition of the must.

It is possible to outline the evolution from the samples at the beginning of the first fermentation, characterised by a high sugar content and $\mathrm{pH}$ and by low ABV, TA and VA (Table 3) and located on the left-hand-side on the plot. The slight chemical difference in the composition of V1 and V2 is evident, as well as in their subsequent corresponding samples (V1a and V2a). The blend (sample T) is positioned exactly on the segment that connects V1a and V2a. Sample $\mathrm{A}$ is placed alone, with positive scores on PC1 and negative ones on PC2, and is characterised by a high concentration of a lot of the aroma compounds, for example the long chain acids, their ethyl esters, and C6 alcohols (1-hexanol and trans-3-hexenol). Samples A1, A2, and A3, sampled during the second fermentation, all have positive scores on both the PCs. They are characterised by positive loading values

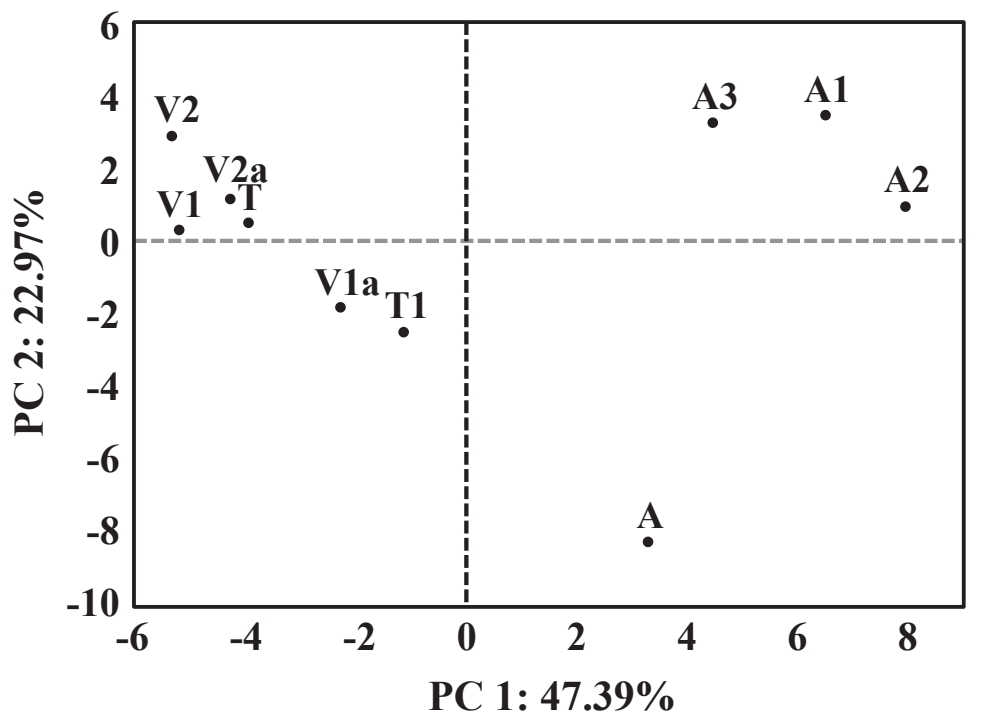

FIGURE 2

Principal component analysis of the samples. Plot of the first two principal components (PC1 vs. PC2) with the respective explained variances; V1 and V2 (5 October), V1a and V2a (12 October), blend: T (16 October), T1 (28 October), second fermentation in autoclave: A (4 November), A1 (13 November), A2 (16 November), A3 (20 November). 
of ABV, TA, propanol, 1-butanol, 3-methyl-1-pentanol, 3 -ethoxypropanol and some of short chain acids in both the PCs, and by negative loading values of reducing sugar and pH. Finally, PC3 (10\% of total variance) introduces only a little bit of additional information, mainly due to loading values of some of the minor compounds, such as linalool oxides, diacetyl and diethyl succinate (Table 3).

\section{CONCLUSIONS}

The characterisation of volatile compounds in Malvasia di Candia aromatica wine is a first approach to the study of the complexity of this aromatic cultivar and the evolution of aroma during the winemaking process. In general, the evolution of the total aromatic compounds follow an increasing trend, in agreement with the progress of fermentation. However, some classes of compounds, such as monoterpenes, showed a less regular trend, particularly during the second fermentation in the autoclave. Monoterpenes are of great importance for Malvasia di Candia aromatica. These compounds are fundamental for the sensory quality of this wine, as in some cases their concentration largely outnumbers the ThP. This is the case of linalool in particular, and of nerol. Elucidating the evolution of the aroma during wine production can contribute to discovering the steps at which it is possible to act in order to preserve, or even better - enhance, the wine varietal bouquet. For this reason a more in-depth study of the control and optimisation of the technological parameters of winemaking, such as temperature, selected yeasts, influence of clarifications, use of glycolytic enzymes, etc., should be carried out.

\section{LITERATURE CITED}

Bavaresco, L., Gatti, M., Pezzutto, S., Fregoni, M. \& Mattivi, F., 2008. Effect of leaf removal on grape yield, berry composition and stilbene concentration. Am. J. Enol. Vitic. 59, 292-298.

Beltran, G., Novo, M., Guillamón, J.M., Mas, A. \& Rozès, N., 2008. Effect of fermentation temperature and culture media on the yeast lipid composition and wine volatile compounds. Int. J. Food Microbiol. 121, 169-177.

Borsa, D., Carniel, D., Asproudi, A, Ponticelli, L., Crespan, M. \& Costacurta, A., 2005. Characterization of Malvasia grapes by secondary metabolites. Riv. Vit. Enol. 2-3-4, 167-182.

Calò, A., Scienza, A. \& Costacurta, A., 2006. Malvasia di Candia aromatica In: Calò, A., Scienza, A. \& Costacurta, A. (eds). Vitigni d'Italia. Le varietà tradizionali per la produzione dei vini moderni. Edagricole, Bologna, Italy. pp. $498-499$.

Câmara, J.S., Alves, M.A. \& Marques, J.C., 2007. Classification of Boal, Malvazia, Sercial and Verdelho wines based on terpenoid patterns. Food Chem. 101, 475-484.

Câmara, J.S., Herbert, P., Marques, J.C. \& Alves MA, 2004. Varietal flavour compounds of four grape varieties producing Madeira wines. Anal. Chim. Acta 513, 203-207.

Costacurta, A., Calò, A., Carraro, R., Giust, M. \& Crespan, M., 2005. The Malvasias cultivated in Italy: Molecular, ampelographic, chemical profiles and pedigree relationships. Riv. Viticol. Enol. 58, 55-65.

Del Caro, A., Fanara, C., Genovese, A., Moio, L., Piga, A. \& Piombino, P., 2012. Free and enzymatically hydrolysed volatile compounds of sweet wines from Malvasia and Muscat grapes (Vitis vinifera L.) grown in Sardinia. S. Afr. J. Enol. Vitic. 33, 115-121.
D'Onofrio, C., 2011. Functional characterization of the biosynthesis of the aroma of grapes during the berry development and evaluation of aromatic quality of grapes [Caratterizzazione funzionale della biosintesi degli aromi delle uve durante lo sviluppo dell'acino e controllo della qualità aromatica delle uve]. Italus Hortus 18, 39-61.

EU Official Gazette, 1990. L 272, Luxembourg, October 3.

Fenoll, J., Manso, A., Hellín, P., Ruiz, L. \& Flores, P., 2009. Changes in the aromatic composition of the Vitis vinifera grape Muscat Hamburg during ripening. Food Chem. 114, 420-428.

Ferreira, V., López, R. \& Cacho, J.F., 2000. Quantitative determination of the odorants of young red wines from different grape varieties. J. Sci. Food Agr. 80, 1659-1667.

Gerbi, V., Zeppa, G. \& Carnacini, A., 1992. Rapid extraction of volatile compounds in wine and vinegar using Extrelut resin. Ital. J. Food Sci. 4, 259-267.

Giust, M., Costacurta, A., Carraro, R., Aggio, L. \& Morbin, E., 2005. Malvasias in the collection of Istituto Sperimentale per la Viticultura. Results of twenty years of phenologic and productive observations. Riv. Viticol. Enol. 58, 67-80.

Gómez-Plaza, E., Gil-Muñoz, R., Carreño-Espín, J., Fernández-López, J.A. \& Martínez-Cutillas, A., 1999. Investigation on the aroma of wines from seven clones of Monastrell grapes. Eur. Food Res. Technol. 209, 257-260.

Gunata, Y.Z., Bayonove, C.L., Baumes, R.L. \& Cordonnier, R.E., 1986. Stability of free and bound fractions of some aroma components of grapes cv. Muscat during the wine processing: Preliminary results. Am. J. Enol. Vitic. 37, 112-114.

Gunata, Y.Z., Bitteur, S., Brillouet, J.M., Bayonove, C. \& Cordonnier, R., 1988. Sequential enzymic hydrolysis of potentially aromatic glycosides from grape. Carboh. Res. 184, 139-149.

Guth, H., 1997. Quantitation and sensory studies of character impact odorants of different white wine varieties. J. Agr. Food Chem. 45, $3027-$ 3032 .

Lacombe, T., Boursiquot, J.-M., Laucou, V., Dechesne, F., Varès, D. \& This, P., 2007. Relationships and genetic diversity within the accessions related to Malvasia held in the domaine de vassal grape germplasm repository. Am. J. Enol. Vitic. 58, 124-131.

Lafon-Lafourcade, S., Geneix, C. \& Ribéreau-Gayon, P., 1984. Inhibition of alcoholic fermentation of grape must by fatty acids produced by yeasts and their elimination by yeast ghosts. Appl. Environ. Microbiol. 47, 1246-1249.

Liberatore, M.T., Pati, S., Del Nobile, M.A. \& La Notte, E., 2010. Aroma quality improvement of Chardonnay white wine by fermentation and ageing in barrique on lees. Food Res. Int. 43, 996-1002.

Masino, F., Montevecchi, G., Arfelli, G. \& Antonelli, A., 2008. Evaluation of the combined effects of enzymatic treatment and aging on lees on the aroma of wine from Bombino bianco grapes. J. Agr. Food Chem. 56, 9495 9501.

Meneghetti, S., Poljuha, D., Frare, E., Costacurta, A., Morreale, G., Bavaresco, L. \& Calò, A., 2012. Inter- and intra-varietal genetic variability in Malvasia cultivars. Mol. Biotechnol. 50, 189-199.

Miller, A.C., Wolff, S.R., Bisson, L.F. \& Ebeler, S.E., 2007. Yeast strain and nitrogen supplementation: Dynamics of volatile ester production in Chardonnay juice fermentations. Am. J. Enol. Vitic. 58, 470-483.

Molina, A.M., Swiegers, J.H., Varela, C., Pretorius, I.S. \& Agosin, E., 2007. Influence of wine fermentation temperature on the synthesis of yeast-derived volatile aroma compounds. Appl. Microbiol. Biotechnol. 77, 675-687.

Muratore, G., Nicolosi Asmundo, C., Lanza, C.M., Caggia, C., Licciardello, F. \& Restuccia, C., 2007. Influence of Saccharomyces uvarum on volatile acidity, aromatic and sensory profile of Malvasia delle Lipari wine. Food Technol. Biotechnol. 45, 101-106. 
Nicolini, G., Moser, S., Larcher, R., Versini, G. \& Fedrizzi, B., 2009. Technological characterization of Malvasia colli di Parma doc juice and wine. In: Malvasias (ed.): Proc. $3^{\text {rd }}$ Internat. Symp. "Malvasias", May 2009, La Palma, Canary Islands, Spain. p. 10.

Ough, C.S. \& Amerine, M.A., 1988. Methods for analysis of must and wines. Wiley, New York.

Rapp, A. \& Mandery, H., 1986. Wine aroma. Experientia 42, 873-884.

Rapp, A. \& Versini, G., 1996. Flüchtige phenolische Verbindungen in Wein (Volatile phenolic compounds of wine). Deut. Lebensm-Rundsch. 92, 4248.

Ribéreau-Gayon, P., Boidron, J.N. \& Terrier, A., 1975. Aroma of Muscat grape varieties. J. Agr. Food Chem. 23, 1042-1047.
Scalabrelli, G., Ferroni, G., Zinnai, A., Venturi, F. \& Andrich, G., 2008. Sensorial characteristics of wines obtained from late harvest of grapevine variety Malvasia di Candia aromatica in Tuscany. Riv. Viticol. Enol. 2, 409 422.

Shinohara, T., 1985. Gas chromatographic analysis of volatile fatty acids in wines. Agr. Biol. Chem. 49, 2211-2212.

Vianna, E. \& Ebeler, S.E., 2001. Monitoring ester formation in grape juice fermentations using solid phase microextraction coupled with gas chromatography-mass spectrometry. J. Agr. Food Chem. 49, 589-595.

Vilanova, M., Genisheva, Z., Masa, A. \& Oliveira, J.M., 2010. Correlation between volatile composition and sensory properties in Spanish Albariño wines. Microchem. J. 95, 240-246.

Zamboni, M., Fregoni, M. \& Civardi, S., 2009. Terroirs and wines of Malvasia di Candia aromatica. Riv. Viticol. Enol. 2, 25-35. 